Original Research

\title{
The Feasibility of Using Vegetation Indices and Soil Texture to Predict Rice Yield
}

\author{
Hadis Yaghouti ${ }^{1}$, Ebrahim Pazira ${ }^{1}$, Ebrahim Amiri ${ }^{2 *}$, Mohammad Hasan Masihabadi ${ }^{3}$ \\ ${ }^{1}$ Department of Soil Science, Faculty of Agriculture and Natural Resources, Science and Research Branch, \\ Islamic Azad University, Tehran, Iran \\ ${ }^{2}$ Department of Water Engineering, Lahijan Branch, Islamic Azad University, Lahijan, Iran \\ ${ }^{3}$ Soil and Water Research Institute, Tehran, Iran
}

Received: 4 October 2017

Accepted: 8 December 2017

\begin{abstract}
Identifying plant-environment interactions along with remote sensing provides grounds for designing management methods as well as predicting rice yield in different conditions; accordingly, it is very helpful to use vegetation indices for identifying the vegetation and greenness of farms. The regression between the local and high-yield varieties of rice in 2012 and the NDVI, SAVI, LAI, DVI, and RVI indices derived from Landsat 7 in northern Iran indicate the superiority of the NDVI index in the flowering stage of rice. Results show that the coefficient of determination of the fitted model for local and high-yielding varieties is 0.71 and 0.70 , respectively, which indicates the good consistency of the results with the regional data. We evaluated the models for the local and high-yielding varieties in crop year 2013 with RMSE of 406 and $272 \mathrm{~kg} \mathrm{ha}^{-1}$ and NRMSE of $12 \%$ and 6\%, respectively. Moreover, the simulation results show that the yield of the models is well fitted with the observed values; besides, there is high correlation $(\mathrm{R}>0.80)$ between the real and predicted yield values. As shown by the investigation of the region's soil texture, the fine-texture paddy fields have better yield.
\end{abstract}

Keywords: crop yield, remote sensing, rice, vegetation indices

\section{Introduction}

Crop monitoring is of great importance in the economic development of any country due to the production of crops and predicting annual yield having direct effects on the national and international economies and playing an important role in food management [1]. Therefore, it is essential to perform

*e-mail: eamiri57@yahoo.com the early estimation of crops and provide the resulting information for planners of the agricultural sector [2].

Today the assessment of different production options, extrapolation, and generalization of the results to other regions with different climates and conditions can be accomplished through simulating the production process [3]. Soil is considered as the base of production security; thus, in order to achieve more effective crop management programs, yield-limiting soil features should be taken into account [4]. Soil properties vary over time and space. The soil spatial variations are naturally caused by soil-forming factors [5] and are 
affected by two factors, namely intrinsic (soil-forming factors such as parent material) and external (agricultural management practices such as fertility and irrigation) properties [6]. The relationship between crop yield and soil is very complicated and depends on the interactions between the physical and chemical properties of soil as well as natural external factors; thus, soil texture can have a variant relationship with crop yield [7-8].

By providing the spatial information of large areas, remote sensing has provided users with the opportunity to predict crop yield before harvesting [9-10]. Plant production is directly dependent on the interactions between solar energy and plant surface [11]; thus, remote sensing techniques can help determine plant production by measuring this energy $[10,12]$. One of the most efficient methods for monitoring agricultural products is to use spectral indices [13-14]. Most of the indices, which are used to estimate the yield, use the red band and near-infrared (NIR) within their structure [10, $15]$, and the modeling process is performed based on the vegetation indices (VI) derived from remote sensing data [16-17]. Numerous studies have investigated how to use this technology $[9-11,13,14,18]$.

Rice is among the most important agricultural crops and is the main food source for more than half of the world's population [10]. Furthermore, in Iran the coastal areas of the Caspian Sea account for more than $70 \%$ of paddy fields [19]. Various studies have indicated that rice farming is common in a wide range of climatic and hydrological features. The soil substrate of rice farming can tolerate the texture range of clay to sand, $\mathrm{pH}$ of $3-10$, organic matter of $1-50 \%$, salinity of $0-1 \%$, as well as low- (under-nutrient) and high-nutrient (over-nutrient) conditions [20].

Identifying plant-environment interactions along with remote sensing technology facilitates designing management methods as well as predicting rice yield in different conditions. Sanchez [21] showed that the amount of crop could be tripled by appropriate soil management; moreover, the study conducted by Juhos et al. [7] indicated that the effects of soil properties depended on grain yield, weather, and topography.

Following the studies conducted on vegetation indices and considering the region's soil potentials for rice production would help estimate the pre-harvesting yield. Similar studies have been conducted to estimate wheat yield using spectral indices, which have led to favorable results $[17,22]$. The study conducted by Weiguo et al. [11] in China to estimate rice yield using HJ1A satellite imaging indicated the closeness of the real and estimated values of the model so that the model could predict the yield up to $85 \%$.

Moreover, by establishing a direct relationship between the vegetation indices derived from the SPOT satellite imagery and rice yield in a small research farm, Aboelghar et al. [23] could predict the yield one month before harvesting $\left(\mathrm{R}^{2}=0.86\right)$. Nuarsa et al. [12] employed NDVI index resulted from Landsat ETM+ satellite imagery to present an exponential model for estimating the rice yield $\left(\mathrm{R}^{2}=0.852\right)$. Assessment of the model indicated a strong relationship between the observations and estimated data.

In another study, Noureldin et al. [16] used the normalized difference vegetation index (NDVI) combined with the leaf area index (LAI) to estimate the rice yield, the result validation of which indicated the high precision of the model that could be implemented in similar environmental conditions and the same rice farming methods. Moreover, in Vietnam, Son et al. [10] used the rice yield during 2002-2011 and the NDVI and EVI indices derived from the MODIS satellite for extracting the model, the results of which approved the relationship between the assessed indices and rice yield.

In another study, Siyal et al. [9] attempted to estimate the rice yield in 2013 using the NDVI and RVI indices derived from 8-year Landsat ETM+ satellite imagery. Their proposed regression model was applied between the values of the harvested crop and the NDVI and RVI indices at the peak of greenness period with the determination coefficients $\left(\mathrm{R}^{2}\right)$ of 0.94 and 0.875 , respectively, in order to estimate the yield. The strong relationship between the produced and predicted rice crop confirmed the model's capability to estimate the yield.

In wide ranges of spatial variations and diversity, the factors affecting the yield, including soil type and crop management, can result in errors of estimating the yield because it is impossible to control all the environmental conditions. The use of satellite imagery and groundbased observational data is an appropriate integration for yield assessment. Investigating the NDVI, SAVI, LAI, DVI, and RVI indices and calculating them at the given dates provide the possibility of choosing an appropriate index for the studied region and the ground for monitoring the plant's growth as well as yield accuracy of the indices with regard to the measured plant's growth phase and identifying the soil properties in the region.

\section{Materials and Methods}

\section{Region and Field Data}

Shaft County in southwest Guilan Province is located between $36^{\circ} 56^{\prime}-37^{\circ} 18^{\prime} \mathrm{N}$ latitude and $49^{\circ} 10^{\prime}-49^{\circ} 31^{\prime} \mathrm{E}$ longitude in northern Iran. The area of the studied region embraces nearly 14000 ha of the total area of the city undergoing rice farming. The region is temperate and humid and the paddy fields are located in plains and foothills (Fig. 1).

The rice varieties in the farms of this region are categorized into two major groups, including local varieties, namely Hashemi and Ali Kazemi, and highyielding (modified) varieties, namely Khazar and Gohar. In fact, the local varieties account for two-third of the paddy fields. In the present research, the ratio of the varieties was maintained besides the proper distribution 



Fig. 1. Geographic location of study area in the city of Shaft, Guilan, Iran.

of the farms across the region. Thus, data of the farms, including type of variety, yield value, area of rice paddies, and onset dates of planting and harvesting, were received during two years (2012 and 2013). Then the results were compared with the available maps of land use and differentiation of the agricultural products. The data of the first and second years were used for deriving the equations and evaluating the best extracted equations, respectively.

Duration of rice farming period in the region for different varieties was 120-150 days, and the paddy fields should be flooded within 90 days from the beginning of cultivation. In the north of Iran, this period coincided with the beginning of April up to August [24]. Table 1 represents the raining status and temperature in the rice-farming period; furthermore, Fuman Water Channel was used for irrigation.

Sampling the surface soil of the paddy fields was performed from the depth of $0-30 \mathrm{~cm}$ at 100 points of the region. The samples were tested after being dried in the open space and being passed through a $2 \mathrm{~mm}$ sieve. The soil texture was hydrometric the soil particle-size distribution was determined for each sample using the hydrometer method from which the soil textural classes were obtained [8]. Organic material was using wet oxidation [5]. Electrical conductivity (EC) and $\mathrm{pH}$ were measured in saturated extract using a conductimeter and electrode methods, respectively [4].

\section{Satellite Data}

Among the environmental satellites, Landsat with multi-spectral scanners and the capability of providing satellite imagery with spatial resolution of less than $30 \mathrm{~m}$ is widely used for the biophysical parameters of vegetation [12]. In addition, the images of this sensor are appropriate for investigating the vegetation status [9] and monitoring plant growth [14] due to the 16-day visit period.

In order to determine the appropriate time for receiving the satellite imagery with regard to the agricultural calendar of rice planting and harvesting as well as the information available in the Department of Agriculture, flowering time and the maturity stage

Table 1. Monthly temperature and rain in tested years.

\begin{tabular}{|c|c|c|c|c|c|c|}
\hline Year & Parameter & April & May & June & July & August \\
\hline \multirow{2}{*}{2012} & Temp $\left({ }^{\circ} \mathrm{C}\right)$ & 17.3 & 22.6 & 24.6 & 25.2 & 26.6 \\
\cline { 2 - 7 } & Rain $(\mathrm{mm})$ & 67.8 & 30.2 & 116.2 & 76.8 & 89.4 \\
\hline \multirow{2}{*}{2013} & $\operatorname{Temp}\left({ }^{\circ} \mathrm{C}\right)$ & 15.7 & 21.8 & 25.7 & 26.7 & 25.4 \\
\cline { 2 - 7 } & Rain $(\mathrm{mm})$ & 58.1 & 25.7 & 8.3 & 58.2 & 49.8 \\
\hline
\end{tabular}


were specified in the second halves of June and July, respectively. The multi-spectral digital data of ETM+ sensor of Landsat 7 were used from route 166 and row 34 in accordance with World Reference System (WRS) on 15 June and 17 July 2012 and 18 June 2013.

Due to system failure, the ETM+ data contained bands without information, since 2003 onwards and a part of the studied region were located in this area. In order to fill the bands, gap-fill tool was added to ENVI v.4.7 software and the images were corrected. Furthermore, the radiometric and geometric corrections were made based on the specified points using Google Earth images in this software. The reflectance values in the third and fourth bands were obtained as red equal to $650 \mathrm{~nm}$ and NIR equal to $860 \mathrm{~nm}$ [13], respectively, for the above-mentioned images. Finally, the NDVI, SAVI, LAI, DVI, and RVI indices were calculated using the equations that will be introduced in the following section based on the proposed coefficients:

$$
\begin{gathered}
\mathrm{NDVI}^{1}=\frac{\rho_{\text {nir }}-\rho_{\text {red }}}{\rho_{\text {nir }}+\rho_{\text {red }}} \\
\mathrm{SAVI}^{2}=\frac{\rho_{\text {nir }}-\rho_{\text {red }}(1+L)}{\left(\rho_{\text {nir }}+\rho_{\text {red }}+L\right)} \\
\mathrm{LAI}^{3}=-\frac{\operatorname{Ln}\left(\frac{C_{1}-S A V I}{C_{2}}\right)}{C_{3}} \\
\mathrm{DVI}^{4}=\rho_{\text {nir }}-\rho_{\text {red }} \\
\mathrm{RVI}^{5}=\frac{\rho_{\text {red }}}{\rho_{\text {nir }}}
\end{gathered}
$$

$\mathrm{P}_{\text {nir }}$ and $\mathrm{P}_{\text {red }}$ values in order of reflectivity were in the red and NIR bands $[9,25]$. The value of coefficient $L$ was calculated equal to 0.1 with regard to the regional studies; moreover, C1, C2, and C3 constant coefficients, the values of which depend on the type of product, were considered equal to $0.69,0.59$, and 0.91 , respectively, for the rice plant [26].

\section{Statistical Indices}

The information obtained from the paddy fields in 2012 was divided into two parts. The first part

\footnotetext{
Normalized Difference Vegetation Index [27]

2 Soil Adjusted Vegetation Index [28]

3 Leaf Area Index [29]

4 Difference Vegetation Index [30]

5 Ratio Vegetation Index [31]
}

containing 75 positions was used to extract the regression equations of the local and high-yielding varieties and the second part including 25 data was used for validating the equations. Accuracy of the images in predicting the yield was evaluated using the statistics of the root mean square error (RMSE), normalized RMSE (NRMSE), mean bias error (MBE), and coefficient of determination $\left(\mathrm{R}^{2}\right)$. Also, the data of 75 farms in 2013 were used for re-evaluating the best equations derived from the first-year data:

$$
\begin{aligned}
& \operatorname{RMSE}=\left[\frac{\sum_{\mathrm{i}=1}^{\mathrm{n}}\left(\mathrm{P}_{\mathrm{i}}-\mathrm{O}_{\mathrm{i}}\right)^{2}}{\mathrm{n}}\right]^{1 / 2} \\
& \mathrm{NRMSE}=\frac{\mathrm{RMSE}}{\overline{\mathrm{O}}} \times 100
\end{aligned}
$$

$$
\mathrm{MBE}=\frac{\sum_{\mathrm{i}=1}^{\mathrm{n}}\left(\mathrm{P}_{\mathrm{i}}-\mathrm{O}_{\mathrm{i}}\right)}{\mathrm{n}}
$$

...where $\mathrm{P}_{\mathrm{i}}, \mathrm{O}_{\mathrm{i}}, \overline{\mathrm{O}}$, and $\mathrm{n}$ indicate the estimated or replicated values, observational (measured) values, average of the observational (measured) values, and number of samples (observed, calculated or estimated varieties), respectively. The above-mentioned indices have been widely used in various studies, including Son et al. [10] and Siyal et al. [9], for valuation of the models; accordingly, the straight-line equation is drawn for the two models that have allocated the highest regression coefficients.

Moreover, diversity of the soil properties in farms is interpreted using the classical statistical methods [5] and data distribution is demonstrated by mean, minimum, maximum, standard deviation (SD), and coefficient of variations $(\% \mathrm{CV})$. In order to compare the distribution in one or two separate populations, the coefficient of variations is used. The coefficient of variations indicates the data dispersion around the mean; thus, the higher the value of this index, the higher the dispersion of data relative to the mean. Variables with CV of less than $15 \%$ have low variations, while those with $\mathrm{CV}$ of $15-35 \%$ have moderate variations and those with the CV of above $35 \%$ have high variations.

\section{Results and Discussion}

\section{Relationships between Indices and Crop Yield}

Vegetation indices were calculated for local and high-yielding varieties in the region in both flowering and maturity periods based on the ground reflection of the images. In order to find the correlation between the dependent (crop yield or y-axis) and independent variables (vegetation indices or $\mathrm{x}$-axis) as well as the 
Table 2. Relationship between yields of rice varieties and indices in 2012 .

\begin{tabular}{|c|c|c|c|c|c|c|}
\hline Variety & INDEX & Stage crop & MODEL & $\mathrm{R}^{2}$ & $\begin{array}{c}\text { RMSE } \\
\left(\mathrm{Kg} \mathrm{ha}^{-1}\right)\end{array}$ & $\begin{array}{c}\text { NRMSE } \\
(\%)\end{array}$ \\
\hline \multirow{10}{*}{ Local } & \multirow{2}{*}{ NDVI } & Flowering & $Y=4389.5 x+1042.7$ & 0.71 & 310 & 10 \\
\hline & & Maturity & $Y=4594.2 x+792.5$ & 0.61 & 495 & 15 \\
\hline & \multirow{2}{*}{ SAVI } & Flowering & $Y=6640.3 x+27.003$ & 0.65 & 440 & 14 \\
\hline & & Maturity & $Y=6023.7 x+372.91$ & 0.44 & 431 & 14 \\
\hline & \multirow{2}{*}{ LAI } & Flowering & $Y=944.54 x+2111.8$ & 0.60 & 447 & 14 \\
\hline & & Maturity & $Y=899.35 x+2219.2$ & 0.40 & 446 & 14 \\
\hline & \multirow{2}{*}{ DVI } & Flowering & $Y=22.397 x+2172.7$ & 0.65 & 428 & 13 \\
\hline & & Maturity & $Y=26.96 x+2005.4$ & 0.52 & 448 & 14 \\
\hline & \multirow{2}{*}{ RVI } & Flowering & $Y=420.5 x+2001.3$ & 0.65 & 408 & 13 \\
\hline & & Maturity & $Y=472.44 x+1694.8$ & 0.57 & 423 & 13 \\
\hline \multirow{10}{*}{ High-yielding } & \multirow{2}{*}{ NDVI } & Flowering & $Y=3574.1 x+2576.9$ & 0.70 & 321 & 7 \\
\hline & & Maturity & $Y=4103.6 x+2361.5$ & 0.57 & 459 & 10 \\
\hline & \multirow{2}{*}{ SAVI } & Flowering & $Y=5234.8 x+1820.7$ & 0.61 & 506 & 11 \\
\hline & & Maturity & $Y=5256.9 x+1754.4$ & 0.56 & 547 & 12 \\
\hline & \multirow{2}{*}{ LAI } & Flowering & $Y=799.74 x+3396.4$ & 0.62 & 511 & 11 \\
\hline & & Maturity & $Y=757.23 x+3401.4$ & 0.60 & 554 & 12 \\
\hline & \multirow{2}{*}{ DVI } & Flowering & $Y=14.908 x+3618.2$ & 0.65 & 375 & 8 \\
\hline & & Maturity & $Y=15.953 x+3514.9$ & 0.58 & 455 & 10 \\
\hline & \multirow{2}{*}{ RVI } & Flowering & $Y=278.39 x+3459.3$ & 0.65 & 422 & 9 \\
\hline & & Maturity & $Y=334.33 x+3258.8$ & 0.48 & 442 & 9 \\
\hline
\end{tabular}

model fit, the linear regression model was used. The ANOVA results showed that the relationship between vegetation indices and rice yield was significant $($ Sig $<0.05)$. Statistical criteria of the equations between the yield of rice varieties and vegetation indices derived from the images are shown in Table 2.

As seen in Table 2, the highest value of the coefficient of determination $\left(\mathrm{R}^{2}\right)$ of the equations derived for local varieties was related to the flowering period and NDVI index. Other indices have lower coefficient of determination and lacked favorable precision for estimating the yield. Measurement error for the NDVI index in flowering period was $10 \%$, which was equivalent to $310 \mathrm{~kg} \mathrm{ha}^{-1}$ (Fig. 2).

Investigating the regression relationships between the plant parameters and yield for high-yield varieties (Table 2) indicated that the NDVI index equation extracted from the flowering period images with the determination coefficient of 0.70 had maximum coordination with the production yield of the varieties. Validation of the model indicated the measurement error of $7 \%$ equivalent to $321 \mathrm{~kg} \mathrm{ha}^{-1}$, which was more accurate than other equations.

As inferred from the observation of the table, the highest coefficient of determination between the production yield and indices existed in the flowering period. Besides, among the studied indices, the NDVI index was the most favorable criterion for estimating the local and high-yield varieties' yield in the region. Furthermore, the diagram of the models proposed for estimating the yield of the studied varieties using NDVI index was shown; however, due to the decreased correlation of the other indices, their diagrams were not drawn, but the coefficient of determination and error of equations are presented in Table 2.

Based on the obtained results, it can be found that by approaching the end of the growth season, the relationship of the indices extracted from the satellite images with the plant variables is reduced so that the indices obtained from the maturity period images do not have favorable efficiency for yield estimation. The difference in reflectance rate distinguishes the objects from each other and the presence of water, and moisture affects the reflectance rate of the electromagnetic spectrum; thus, at the final stage of rice growth (on almost the 100th day), after completion of the clustering levels and, finally, formation of the seeds leading to the heaviness of the clusters, the plant is laid down and the seeds lose water. Since the studied vegetation indices result from the reflection of the red and NIR bands and 

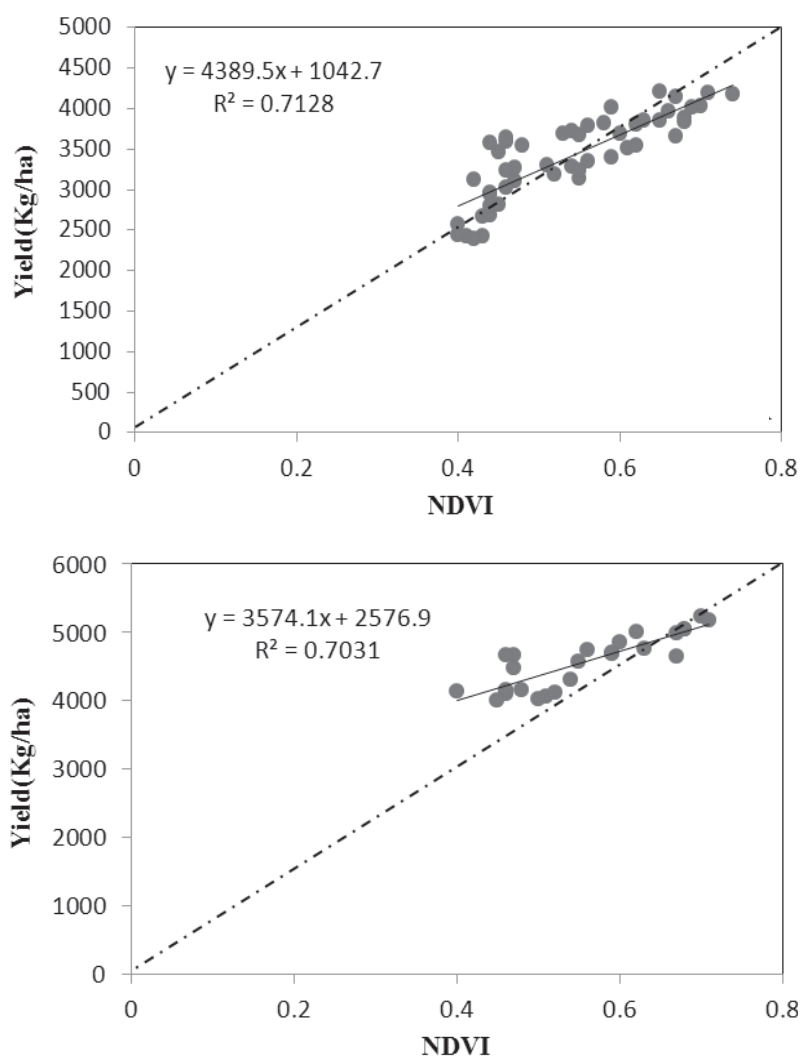

Fig. 2. Relationship between NDVI and productive performance in 2012: a) local rice and b) high-yield rice.

the maximum chlorophyll absorption occurs in these two bands [13, 32], the relationship of this index with the growth of plants and vegetation can be justified. Nuarsa et al. [12], Son et al. [10], and Siyal et al. [9] have also reported high precision of the NDVI index for yield estimation.

As previously stated, the images were taken at the peak of the plant's growth; as a result, since the soil surface was covered, the SAVI index that was developed to reduce the background soil reflectance from the plant reflectance could not provide precision better than that of the NDVI index. Moreover, the equations derived from LAI had less precision than other equations, which seems to be due to the linear relationship. Many attempts have been made to increase the coefficient of determination of the relationship between LAI and rice yield so that even Noureldin et al. [16], by designing a bivariate (bi-variable) regression model (NDVI and LAI indices), tried to increase the precision of the proposed linear model, which led to acceptable results. Another important point is to use the coefficients presented in the references for calculating the LAI index in the present research, which might increase the error rate. Apropos of the DVI and RVI indices, some studies have been conducted to help estimate the yield along with other common indices [9, 11, 16, 23], leading to good results; thus, in the present research, they were next to the NDVI index in terms of precision.

\section{Assessing Proposed Equation}

Table 3 shows the results of the proposed equation's efficiency for 75 data taken from the farms in 2013. In estimating the yield of the local varieties by the model, a slight difference could be seen between the model's average yield and the observed values, and it can be said that the model's estimation accuracy in the average yield range was high and the obtained results were similar to the reality, but for the above average yield range, the yield value was underestimated; on the other hand, for the below average range, the model yield was overestimated so that the model tended toward the average. As for the high-yielding varieties, as shown in Table 3, the model provided values above the real values for estimating the average and minimum yield, just like the local varieties. In other words, the yield range of the estimated data was lower than the observational data. In other words, the MBE index showed that the model overestimated the yield value in this region [9].

In evaluating the yield estimation accuracy of the images of the flowering period for the proposed model of the local varieties, the RMSE and NRMSE values were $406 \mathrm{~kg} \mathrm{ha}^{-1}$ and $12 \%$, respectively, and the accuracy rate was slightly reduced compared to the validation period. As for the proposed model for the high-yielding varieties of the region, the measurement error was $6 \%$ equivalent to $272 \mathrm{~kg} \mathrm{ha}^{-1}$. The NRMSE value for both categories was in the favorable range [10] and did not exceed 12\%.

The simulation results indicated that the models' yields were well fitted with the observed values and the high correlation could be seen $(\mathrm{R}>0.80)$ between the real and predicted values. Nuarsa et al. [12] also reported the high correlation of the predicted values

Table 3. Results of the model in the city in 2013.

\begin{tabular}{|c|c|c|c|c|c|c|c|c|c|c|}
\hline Variety & $\begin{array}{l}\text { Variable } \\
\text { plant }\end{array}$ & Model & $\begin{array}{c}\text { Mean } \\
(\mathrm{Kg} / \mathrm{ha})\end{array}$ & $\begin{array}{c}\text { Min } \\
(\mathrm{Kg} / \mathrm{ha})\end{array}$ & $\begin{array}{c}\text { Max } \\
(\mathrm{Kg} / \mathrm{ha})\end{array}$ & $\begin{array}{l}\text { Range } \\
\text { (Kg/ha) }\end{array}$ & $\mathrm{R}^{2}$ & $\begin{array}{l}\text { RMSE } \\
\text { (Kg/ha) }\end{array}$ & $\begin{array}{c}\text { NRMSE } \\
(\%)\end{array}$ & $\mathrm{MBE}$ \\
\hline \multirow[b]{2}{*}{ Local } & Observed & - & 3502 & 2190 & 4380 & 2190 & - & - & - & - \\
\hline & Estimated & $\begin{array}{c}\mathrm{Y}= \\
4389.5 \mathrm{NDVI}+1042.7\end{array}$ & 3594 & 2842 & 4159 & 1317 & 0.70 & 406 & 12 & 92 \\
\hline \multirow{2}{*}{$\begin{array}{l}\text { High- } \\
\text { yielding }\end{array}$} & Observed & - & 4649 & 4022 & 5280 & 1258 & - & - & - & - \\
\hline & Estimated & $\begin{array}{c}\mathrm{Y}= \\
\text { 3574.1NDVI+2576.9 }\end{array}$ & 4800 & 4435 & 5150 & 715 & 0.66 & 272 & 6 & 151 \\
\hline
\end{tabular}




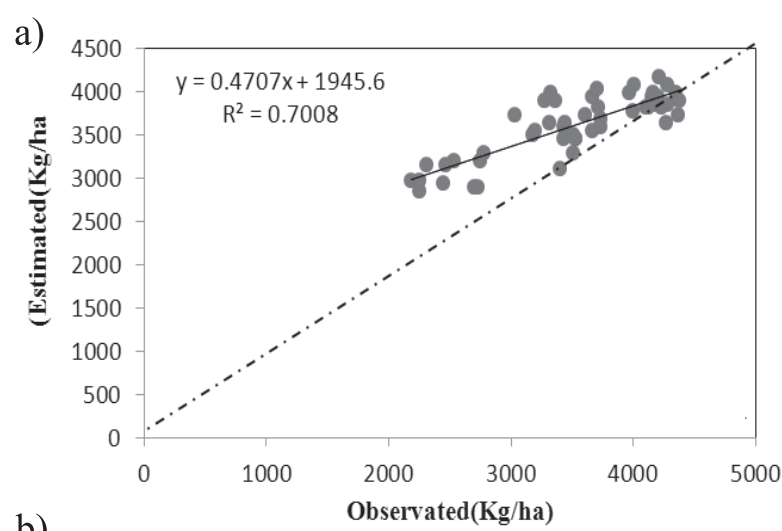

b)



Fig. 3. Comparison of observed yield with estimated yield: a) local rice and $b$ ) high-yield rice.

using remote sensing for rice plants. The coefficient of determination of 0.70 and 0.66 (Fig. 3) between the real and estimated yields could be due to the changed crop conditions and crop management, pests and plant diseases, local weather conditions, and many other environmental variables; for example, heavy rainfall at an inappropriate time not only reduces the crop, but also disrupts the yield prediction process by creating a cloudy atmosphere in the images of the region. However, the data of consecutive years can be used on larger scales in order to improve accuracy.

Finally, after analyzing the results, it should be noted that due to the importance of regional yield estimation, the ETM+ sensor is capable of producing the favorable data with desirable efficiency and the images taken by this sensor would provide a real representation of the crop status as Nuarsa et al. [12], Matinfar [17], Mosleh et al. [2], and Siyal et al. [9] have also considered the use of these images to be useful in their studies.

\section{Relationship between Soil Properties and Yield}

Soil texture is the percentage ratio of soil components, including sand, silt, and clay, which determines the soil texture class in a texture triangle [8]. Among the physical properties, soil texture has significant effects on important features such as growth of the plant and development of underground organs. Furthermore, soil texture is one of the indices influenced by many physical and behavioral features of the soil, including water retention ability, nutrient-preserving capacity, and susceptibility to erosion $[8,33]$.

It is of great importance to understand the distribution of soil properties on the farm scale for improving the agricultural management practices and assessing the agricultural effects on the environment [5]. Based on the results of the soil tests, the soil texture of the region includes clay, clay loam, loam, sandy loam, and silt loam classes. The statistical data of the soil properties of the paddy fields, classified in two groups of local and high-yielding varieties, are briefly shown in Table 4.

Table 4. Soil texture properties for local and high-yield rice.

\begin{tabular}{|c|c|c|c|c|c|c|}
\hline Variety & Soil properties & Min (\%) & Max (\%) & Mean (\%) & SD (\%) & CV (\%) \\
\hline \multirow{5}{*}{ Local } & Sand & 16 & 61.60 & 38.94 & 9.28 & 23.83 \\
\cline { 2 - 7 } & Silt & 28 & 61.60 & 42.70 & 10.20 & 23.89 \\
\cline { 2 - 7 } & Clay & 3.60 & 48 & 18.35 & 11.33 & 61.74 \\
\cline { 2 - 7 } & O.C & 0.55 & 3.55 & 2.04 & 0.67 & 32.84 \\
\cline { 2 - 8 } & pH & 4.55 & 7.31 & 6.16 & 0.67 & 10.88 \\
\hline \multirow{5}{*}{ High-yield } & EC & 0.22 & 2.03 & 0.65 & 0.31 & 47.70 \\
\cline { 2 - 8 } & Sand & 22.40 & 66.40 & 44 & 9.74 & 22.14 \\
\cline { 2 - 7 } & Silt & 28.40 & 62.80 & 42.85 & 8.47 & 19.77 \\
\cline { 2 - 8 } & O.C & 4.40 & 41.60 & 13.15 & 9.50 & 72.24 \\
\cline { 2 - 7 } & pH & 0.39 & 3.86 & 2.04 & 0.70 & 34.31 \\
\hline
\end{tabular}


Reviewing the data showed that the variables of clay and electrical conductivity (EC) have high coefficients of variation, implying high variations of the parameters in the region. The clay changes were influenced by the inherent processes of soil, including parent material, $\mathrm{pH}$, climate, and topography. In addition to the inherent processes, the salinity variations were influenced by management (waterlogging, land drainage conditions, fertilizer consumption rate, depth and number of plowings, and burning rice crop residuals). According to the zoning map of the paddy fields, it was observed that the high-yielding farms were mainly located in the suburbs close to the water channels so that this phenomenon could be attributed to the effects of the urban activities on agriculture.

In the statistical investigations on the soil information and crop yield, no direct relationship was observed between the two variables, but it seems that in the finetexture paddy fields, a higher yield was achieved. This phenomenon could be due to the increased CEC as well as the increased specific surface area of the particles; therefore, it is necessary to conduct further studies on the soil science and crop yield reports.

\section{Comparing Real and Potential Yields}

The potential crop growth in a region is determined by genotype and climate, while the real yield results from the interactions of the local growth constraints and the growth reduction factors [34]. The crop yield is influenced by various factors: 1) availability of nutrients in the soil; 2) inputs that are under control of the farmer, including varieties, crop rotation, and weed control; 3) soil properties; and 4) climatic factors that cannot be fully controlled by the farmer [35].

As Wit and Diepen [36] have stated, relying on the spatial distribution of the growth model in the vast regions, the application of the crop yield prediction programs commonly lacks the sufficient certainty in the spatial distribution of soil properties, soil initial conditions, crop parameters, and weather forecasts. Furthermore, continuous cultivation over the years influences the availability of water and nutrients and, consequently, reduces the crop yield by increasing the specific gravity and reducing the fine and coarse pores of the aggregates [37].

Since the soil science information of different regions is not comprehensively available in Iran, it would probably be simpler and more feasible to use the satellite data obtained from different months. Moreover, by separating rice varieties of the paddies in the region into two groups of local and high-yielding varieties, it has been attempted to minimize the difference between the model and the real data. Another important point is that model calibration was carried out using the point data, and model evaluation was performed on a large scale. In research projects, the plant's yield is closer to the potential yield, while on a large scale, the difference of crop management, spatial variations, and parameters affecting the yield, and the type of soil lead to errors in yield estimation [19].

\section{Conclusions}

The present research aimed to predict rice yield. It can be said that choosing an appropriate modeling method does not necessarily mean using complex methods with numerous input factors; but the use of empirical correlations and regression between the plant parameters or soil science with crop yield is preferable to the complex methods due to the convenience of implementation and generalization to other regions. Nevertheless, such simplicity of models should not be defined as their low accuracy. Farm management requires identifying soil texture in order to achieve the optimal consumption of inputs. Besides, due to the importance of rice farming, the local capacities for developing the cultivation of this plant should be identified and the environmental potentials should be used maximally. Results of the present study provide the possibility for planners to easily predict rice yield for the two groups of local and high-yielding varieties with acceptable accuracy by providing images in subsequent years and extracting superior index (NDVI) in the flowering phase. Also, it is an effective step in approaching the real yield to the favorable yield level.

\section{Acknowledgements}

The authors wish to express their sincere thanks to the Agriculture-Jahad in Guilan, Iran for their assistance in facilitating the present research study.

\section{Conflict of Interest}

The authors declare no conflict of interest.

\section{References}

1. PRASAD A., CHAI L., SINGH R., KAFATOS M. Crop yield estimation model for Iowa using remote sensing and surface parameters. International Journal of Applied Observation and Geoinformation, 8, 26, 2006.

2. MOSLEH M.K., HASSAN Q.K., CHOWDHURY E.H. Application of remote sensor in mapping rice area and forecasting its production: A Review. Sensors, 15, 769, 2015.

3. WART J.V., KERSEBAUM K.CH., PENG S.H., MILNER M., CASSMAN K.G. Estimating crop yield potential at regional to national scales. Field Crops Research, 143, 34, 2013.

4. AYOBI S.H., KHORMALI F., SAHRAWAT K.L. Relationships of barley biomass and grain yields to soil properties within a field in the arid region: Use of factor analysis. Acta Agriculturae Scandinavica Section B-Soil and Plant Science, 59, 107, 2009. 
5. AYOUBI SH., MOHAMMAD ZAMANI S., KHORMALI F. Spatial variability of some soil properties for site specific farming in northern Iran. International Journal of Plant Production, 1 (2), 225, 2007.

6. DAVATGAR N., NEISHABOURI M.R., SEPASKHAH A.R. Delineation of site specific nutrient management zones for a paddy cultivated area based on fertility using fuzzy clustering. Geoderma, 173-174, 111, 2012.

7. JUHOS K., SZABO S., LADANYI M. Influence of soil properties on crop yield: a multivariate statistical approach. International Agrophysics, 29, 425, 2015.

8. TUECHE J.R. Relationships between soil physical properties and crop yields in different cropping systems in southern Cameroon. Ph.D Disseration, Faculty of Agricultural Sciences, Institute of Plant Production and Agroecology in the Tropics and Subtropics University of Hohenheim, 146, 2014.

9. SIYAL A.A., DEMPEWOLF J., BECKER-RESHEF I. Rice yield estimation using Landsat ETM+ Data. Journal of Applied Remote Sensing, 9, 16, 2015.

10. SON N.T., CHEN C.F., CHEN C.R., MINH V.Q., TRUNG N.H. A comparative analysis of multitemporal MODIS EVI and NDVI data for large-scale rice yield estimation. Agricultural and Forest Meteorology, 197, 52, 2014.

11. WEI-GUO L., HUA L, LI-HUA Z. Estimating Rice Yield by HJ-1A Satellite Images. Rice Science, 18 (2), 142, 2011.

12. NUARSA I.W., NISHIO F., HONGO CH. Rice yield estimation using Landsat ETM+ data and field observation. Journal of Agricultural Science, 4 (3), 45, 2012.

13. LIN W., FU-CUN ZH., YUAN-SHU J., XIAO-DONG J., SHEN-BIN Y., XIAO-MEI H. Multi-temporal detection of rice phonological stages using canopy spectrum. Rice Science, 21 (2), 108, 2014.

14. CHENG Q., WU X. Mapping paddy rice yield in Zhejiang Province using MODIS spectral index. Turkish Journal of Agriculture and Forestry, 35, 579, 2011.

15. ALI S.M., MOHAMMED M.J. Gap-filling restoration methods for ETM+ sensor images. Iraqi Journal Science, 54 (1), 206, 2013.

16. NOURELDIN N.A., ABOELGHAR M.A., SAUDY H.S., Ali A.M. Rice yield forecasting models using satellite imagery in Egypt. The Egyptian Journal of Remote Sensing and Space Sciences, 16, 125, 2013.

17. MATINFAR H.R. Modeling wheat yield estimation base upon spectral data and field measurement, case study: Razan plain, IRAN. Technical Journal of Engineering and Applied Sciences, 3 (17), 2123, 2013.

18. RAHMAN A., ROYTMAN L., KRAKAUER N.Y., NIZAMUDDIN M., GOLDBERG M. Use of vegetation health data for estimation of Aus rice yield in Bangladesh. Sensors, 9, 2968, 2009.

19. REZAEI M., SHAHNAZARI A., RAEINISARJAZ M., VAZIFEDOUST M. Improving agricultural management in a large-scale paddy field by using remotely sensing data in the CERES-Rice model. Irrigation and drainage, 65, 224, 2016.

20. TALPUR M.A., CHANGYING J.I., JUNEJO S.A., TAGAR A.A. Impact of rice crop on soil quality and fertility. Bulgarian Journal of Agricultural Science, 19 (6), 1287, 2013.

21. SANCHEZ P.A. Tripling crop yields in tropical Africa. Nature Geo-Science, 3, 299, 2010.

22. ZHANG H., CHEN H., ZHOU G. The model of wheat yield forecast based MODIS-NDVI (A case study of
Xinxiang). XXII ISPRS Congress, 25 August - 01 September. Melbourne. Australia, 2012.

23. ABOELGHAR M., ARAFAT S., ABO YOSEF M., ElSHIRBENY M., NAEEM S., MASSOUD A., SALEH N. Using SPOT data and leaf area index for rice yield estimation in Egyptian Nile delta. The Egyptian Journal of Remote Sensing and Space Sciences, 14, 81, 2010.

24. AMIRI LARIJANI B., SARVESTANI Z.T., NEMATZADEH GH., MANSCHADI A.M., AMIRI E. Simulating phenology, growth and yield of transplanted rice at different seedling ages in Northern Iran using ORYZA2000. Rice Science, 18 (4), 321, 2011.

25. PANDA S.S., AMES D.P., PANIGRAHI S. Application of vegetation indices for agricultural crop yield prediction using Neural network techniques. Remote Sensing, 2 (3), 673, 2010.

26. CHOUDHURY B.J., AHMAD N.U., IDSO S.B., REGINATO R.J., DAUGHTRY C.S.T. Relations between evaporation coefficients and vegetation indices studied by model simulations. Remote Sensing of Environment, 50 (1), 1, 1994.

27. ROUSE J.W., HAAS R.H., SCHELL J.A., DEERING D.W. Monitoring vegetation systems in the great plains with ERTS. 3rd ERTS Symposium, NASA SP-351, 1, 309, 1973.

28. HUETE A.R. A soil-adjusted vegetation index (SAVI). Remote Sensing of Environment, 25, 295, 1988.

29. ALLEN R., WATERS R., TASUMI M., TREZZA R., BASTIAANSSEN W. SEBAL, Surface energy balance algorithms for land, Idaho Implementation. Advanced Training and User's Manual, version 1.0, 2002.

30. RICHARDSON A.J., EVERITT J.H. Using spectra vegetation indices to estimate rangeland productivity. Geocarto International, 7 (1), 63, 1992.

31. JORDAN C.F. Derivation of leaf area index from quality of light on the forest floor. Ecology, 50, 663, 1969.

32. EL NAHRY A.H., ALI R.R., EL BAROUDY A.A. An approach for precision farming under pivot irrigation system using remote sensing and GIS techniques. Journal of Agricultural Water Management, 98, 517, 2012.

33. VIDHYA LAKSHMI S., JIJO J., SOUNDARIYA S., VISHALINI T., KASINATHAPANDIAN P. A comparison of soil texture distribution and soil moisture mapping of Chennai coast using landsat ETM + and IKONOS data. Aquatic procedia, 4, 1452, 2015.

34. TITTONELL P., SHEPHERD K.D., VANLAUWE B., GILLER K.E. Unravelling the effects of soil and crop management on maize productivity in smallholder agricultural systems of western Kenya-An application of classification and regression tree analysis. Agriculture, Ecosystems and Environment, 123, 137, 2008.

35. AMAN M.N., BHATTI A.U. Comparison of regression models to predict potential yield of wheat from some measured soil properties. Pakistan Journal of Agricultural Sciences, 52 (1), 239, 2015.

36. WIT A.J.W.D., DIEPEN C.A.V. Crop model data assimilation with the Ensemble Kalman filter for improving regional crop yield forecasts. Agricultural and Forest Meteorology, 146, 38, 2007.

37. ZHONG S., MO Y., GUO G, ZENG H., JIN Z. Effect of continuous cropping on soil chemical properties and crop yield in banana Plantation. Journal of Agricultural Science and Technology, 16, 239, 2014. 
